\title{
Editorial for Special Issue in Honor of InterPore's 10th Anniversary
}

\author{
Lynn Schreyer $^{1} \cdot$ Denis M. O'Carroll ${ }^{2}$-Sridhar Ranganathan ${ }^{3} \cdot$ Mattias Schmidt $^{4}$
}

Published online: 22 August 2019

(c) Springer Nature B.V. 2019

Porous materials are ubiquitous, from biological tissues (skin, cartilage, bones, heart tissue), to manufactured materials (paper, functional porous materials, batteries, drug delivery systems, diapers), to environmental materials (rocks, soils, plants). Because these materials are composed of multiple phases, the effects of flow, heat transfer, chemical reactions, and deformations including swelling and shrinking are more complex than that for a single phase such as a gas, liquid, or solid. The realization that porous materials, regardless of the application, have commonalities in modeling approaches, experimental methods, and numerical methods was the impetus of this journal, Transport in Porous Media (founded by Jacob Bear in 1986) and of the International Society for Porous Media (InterPore, interpore.org), which at its roots, originated in 2006. The growth of TIPM and of InterPore mirrors the explosive interest in porous media research that is now recognized as a field of research in and of itself. It is in the honor of InterPore's 10th anniversary, celebrated at the InterPore 10th Annual Meeting and Jubilee in 2018 in New Orleans, USA, that this special issue was conceived.

The goal of this issue is to help researchers new to porous materials or to certain aspects of porous materials jump into the field as quickly as possible by providing a suite of articles by some of the leading experts in their respective fields in a field-independent manner. We next summarize the history of InterPore and then introduce the contents of this special issue.

InterPore did not just begin one day with a group of people deciding to start an international society. The idea of such a society grew organically, with its origins in a proposal for a joint international graduate research program proposal from the Department of Earth Sciences, Utrecht University, and Institute for Modelling Hydraulic and Environmental Systems, University of Stuttgart, under the leadership of Professor S. Majid Hassanizadeh and Professor Rainer Helmig, respectively, in 2006. The proposal was submitted to DFG and NWO, the research funding agencies of Germany and Netherlands, respectively, and was successfully funded. The research school started its activities on January 1, 2007, under the name Non-linearities and Upscaling in Porous Media (NUPUS). This proved to be so

$凶 \quad$ Lynn Schreyer

Lynn.Schreyer@wsu.edu

1 Department of Mathematics and Statistics, Washington State University, Pullman, WA, USA

2 Water Research Laboratory, UNSW, Sydney, Australia

3 Global Research \& Engineering, Kimberly-Clark Corporation, Roswell, GA 30076, USA

4 Procter \& Gamble Service GmbH, 65824 Schwalbach am Taunus, Germany 


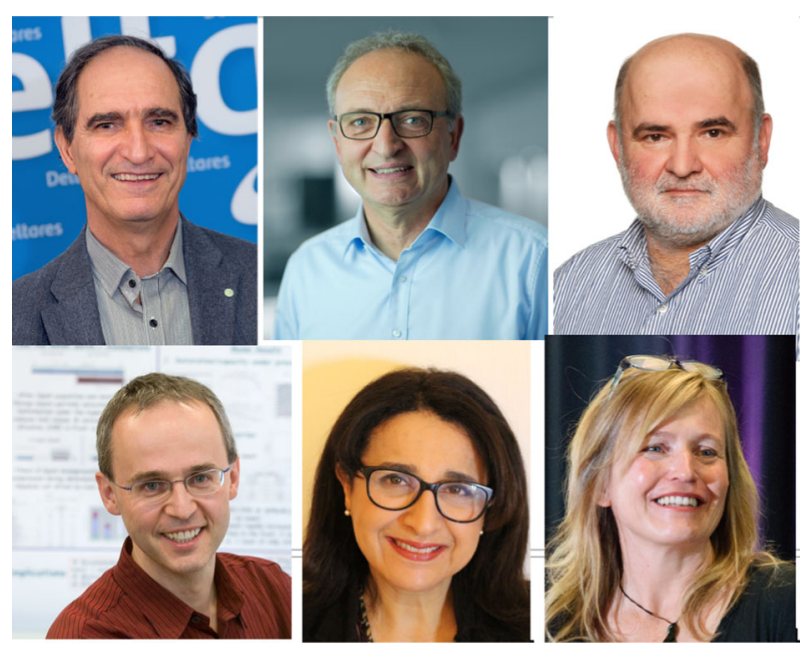

Fig. 1 InterPore members who played a key role in setting up InterPore. Pictured from left: Prof. Majid Hassanizadeh, Prof. Oleg Iliev, Prof. Rainer Helmig, Prof. Azita Ahmadi-Senichault, Dr. Mattias Schmidt, and Prof. Margot Gerritsen

successful at providing an impetus for interaction among participants from a wide range of disciplines that the idea of creating an international center for porous media was born.

As a preamble to the formation of such a center, Majid Hassanizadeh organized a workshop in Utrecht, November 12-17, 2007, entitled Workshop on Flow and Transport in Industrial Porous Media. Though most participants were unknown to each other and worked on seemingly disparate subject areas: fuel cells, filters, biological tissues (both natural and cultured), diapers, soils, paper pulp drying, fabrics and textiles, coal-bed methane production, polymer composites, and $\mathrm{CO} 2$ sequestration, they were studying similar processes, solving similar governing equations, using similar numerical methods, and performing similar experiments and measurements.

Many of the speakers of this workshop expressed interest in meeting in 2008 and setting up a new society. They became the founding members of the Society and met again on April 9, 2008, while attending the NUPUS annual meeting in Utrecht. They agreed to form the European Society for Porous Media, in short Europore, and approved draft bylaws. On May 14, 2008, europore.org website was registered.

As word spread, many non-European scientists expressed interest in joining. So, on July 17,2008 , the geographical scope of the society was expanded and its name was changed to the International Society for Porous Media, with the acronym InterPore. InterPore bylaws were deposited with a public notary, the Society was registered with Utrecht Chamber of Commerce in the fall of 2008, and InterPore started to recruit members. An interim Executive Committee was formed with Professor Rainer Helmig of Stuttgart University as Founding President, Professor Margot Gerritsen of Stanford University as Treasurer, Professor Majid Hassanizadeh as Managing Director, and Dr Mattias Schmidt of Procter \& Gamble as member (Fig. 1). The Executive Committee organized the first InterPore election in 2008 in order to elect eight Council members and the first president-elect. Professor Oleg Iliev of Fraunhofer Institute ITWM became the first elected president of InterPore (Fig. 1). Also, plans were made for holding the first Annual Meeting of InterPore in March 2009 in Kaiserslautern, hosted by Fraunhofer Institute ITWM, and chaired by Oleg Iliev. A strategic alliance agreement was signed with Springer and Transport in Porous Media on Nov. 17, 2008. 
The growth and evolution of InterPore is reflected in the attendance at its meetings and areas represented. At its first meeting in 2009, there were about 90 attendees and 35 talks. At the 4th meeting in 2012 in West Lafayette, IN, there were over 250 speakers and posters. And on the occasion of InterPore's 10th anniversary, held in New Orleans, LA in 2018, there were 468 talks and 289 poster pitch and poster presentations, and over 700 attendees! In parallel, Transport in Porous Media went from publishing 6 issues and 629 pages in 1987 to 15 issues and 3848 pages in 2018.

The articles within this issue are here to help provide a "big picture" of many aspects of porous material research. Some of the articles address modeling: at the macroscale, where the multiple phases are indistinguishable (Battiato et al. 2019), to the pore scale or microscale (Ramstad et al. 2019); modeling of diffusion/dispersion of particles on the order of 10 microns and larger (Tartakovsky and Dentz 2019) and of colloids on the order of a micrometer to nanometers (Molnar et al. 2019); modeling of reactions within porous materials that are limited by lack of mixing of the components (diffusion limited) (Valocchi et al. 2018; Tartakovsky and Dentz 2019); modeling charged porous materials (Joekar-Niasar et al. 2019), fractures (Berre et al. 2018), and heat transfer (Nield and Simmons 2018). Other articles address experimental issues - at the macroscale (Falzone et al. 2018) and fluid displacement at the pore scale (Gerami et al. 2018), while Armstrong et al. (2018) demonstrates how one can go from X-ray microcomputed tomography to characterizing porous media for modeling. And two articles address computational issues: one about open-source software (Bilke et al. 2019) and one about numerical algorithms for large-scale porous media problems (Nägel et al. 2019). Unfortunately, there are some topics that are not addressed in this issue. In particular, deformation of porous materials, wave propagation, percolation, and aspects of multiphase flow through porous media are the most prominent among these. We hope that the articles presented here, however, will take many of you into this rich research environment, where there is still much to be discovered.

\section{References}

Armstrong, R.T., McClure, J.E., Robins, V., Liu, Z., Arns, C.H., Schlüter, S., Berg, S.: Porous media characterization using minkowski functionals: theories, applications and future directions. Transp. Porous Media (2018). https://doi.org/10.1007/s11242-018-1201-4

Battiato, I., Ferrero, V.P.T., O’Malley, D., Miller, C.T., Takhar, P.S., Valdés-Parada, F.J., Wood, B.D.: Theory and applications of macroscale models in porous media. Transp. Porous Med (2019). https://doi.org/10. 1007/s11242-019-01282-2

Berre, I., Doster, F., Keilegavlen, E.: Flow in fractured porous media: a review of conceptual models and discretization approaches. Transp. Porous Med (2018). https://doi.org/10.1007/s11242-018-1171-6

Bilke, L., Flemisch, B., Kalbacher, T., Kolditz, O., Helmig, R., Nagel, T.: Development of open-source porous media simulators: principles and experiences. Transp. Porous Med (2019). https://doi.org/10. 1007/s11242-019-01310-1

Falzone, S., Robinson, J., Slater, L.: Characterization and monitoring of porous media with electrical imaging: a review. Transp. Porous Med (2018). https://doi.org/10.1007/s11242-018-1203-2

Gerami, A., Alzahid, Y., Mostaghimi, P., Kashaninejad, N., Kazemifar, F., Amirian, T., Mosavat, N., Warkiani, M.E., Armstrong, R.T.: Microfluidics for porous systems: fabrication, microscopy and applications. Transp. Porous Med (2018). https://doi.org/10.1007/s11242-018-1202-3

Joekar-Niasar, V., Schreyer, L., Sedighi, M., Icardi, M., Huyghe, J.: Coupled processes in charged porous media: from theory to applications. Transp. Porous Med (2019). https://doi.org/10.1007/s11242-01901257-3

Molnar, I.L., Pensini, E., Asad, M.A., Mitchell, C.A., Nitsche, L.C., Pyrak-Nolte, L.J., Miño, G.L., Krol, M.M.: Colloid transport in porous media: a review of classical mechanisms and emerging topics. Transp. Porous Med (2019). https://doi.org/10.1007/s11242-019-01270-6 
Nägel, A., Logashenko, D., Schroder, J.B., Yang, U.M.: Aspects of solvers for large scale coupled problems in porous media (2019)

Nield, D.A., Simmons, C.T.: A brief introduction to convection in porous media. Transp. Porous Med (2018). https://doi.org/10.1007/s11242-018-1163-6

Ramstad, T., Berg, C.F., Thompson, K.: Pore-scale simulations of single- and two-phase flow in porous media: approaches and applications. Transp. Porous Med (2019). https://doi.org/10.1007/s11242-019-01289-9

Tartakovsky, D.M., Dentz, M.: Diffusion in porous media: phenomena and mechanisms. Transp. Porous Med (2019). https://doi.org/10.1007/s11242-019-01262-6

Valocchi, A.J., Bolster, D., Werth, C.J.: Mixing-limited reactions in porous media. Transp. Porous Med (2018). https://doi.org/10.1007/s11242-018-1204-1

Publisher's Note Springer Nature remains neutral with regard to jurisdictional claims in published maps and institutional affiliations. 